\title{
Análisis multiespectral para la estimación de la turbidez como indicador de la calidad del agua en embalses del estado de Chihuahua, México
}

\section{Multispectral analysis to estimate the turbidity as an indicator of the quality of water in reservoirs in Chihuahua State, Mexico}

\author{
Jesús Amado-Alvarez ${ }^{1}$ \\ Instituto Nacional de Investigaciones Forestales Agricolas y Pecuarias, México \\ Pedro Pérez-Cutillas ${ }^{2}$ \\ Centro de Edafología y Biología Aplicada del Segura, España \\ Luis Carlos Alatorre-Cejudo \\ Universidad Autónoma de Ciudad Juárez, México \\ Orlando Ramírez-Valle 4
}

Instituto Nacional de Investigaciones Forestales Agricolas y Pecuarias, México

1 Doctor en Hidrociencias. Instituto Nacional de Investigaciones Forestales Agricolas y Pecuarias (INIFAPCIRNOC-CESICH). Calle Hidalgo No 1213, Cd. Cuauhtemoc, Chihuahua. C. P. 31500. Correo electrónico: jesusaa@colpos.mx

2 Doctor en Geografía. Centro de Edafología y Biología Aplicada del Segura - Consejo Superior de Investigaciones Científicas (CEBAS-CSIC). Campus Universitario de Espinardo. Espinardo. Murcia, España. CP.30100. Correo electrónico: perezcutillas@cebas.csic.es

3 Doctor en Ordenación del Territorio y Medio Ambiente. Universidad Autónoma de Ciudad Juárez (UACJ). División Multidisciplinaria de la UACJ, Cuauhtémoc, Chihuahua, México. C.P. 31579. Correo electrónico: luis.alatorre@uacj.mx

4 Maestro en Ciencias en administración de los recursos hídricos. Instituto Nacional de Investigaciones Forestales Agricolas y Pecuarias (INIFAP-CIRNOC-CESICH). Calle Hidalgo No 1213, Cd. Cuauhtemoc, Chihuahua. C. P. 31500. Correo electrónico: ramirez.orlando@inifap.gob.mx 
Jesús Amado-Alvarez, Pedro Pérez-Cutillas, Luis Carlos Alatorre-Cejudo, Orlando Ramírez-Valle, Elsa Fabiola Segovia Ortega, Juan José Alarcón-Cabañero. Multispectral analysis to estimate the turbidity as an indicator of the quality of water in reservoirs in Chihuahua State, Mexico

\title{
Elsa Fabiola Segovia Ortega Universidad Politécnica de Gómez Palacio, Durango (México) Juan José Alarcón-Cabañero ${ }^{6}$ Centro de Edafología y Biología Aplicada del Segura, España
}

\begin{abstract}
Resumen
La cuenca del río Conchos, situada en el Estado de Chihuahua (México), ha sufrido un notable deterioro por el desarrollo de las actividades humanas. El crecimiento urbano, la industrialización y la agricultura han degradado de manera notable los recursos hídricos de esta cuenca. Para examinar la calidad de sus aguas se han analizado los embalses de la presa de Las Vírgenes, el lago Colina y la presa la Boquilla, determinando los parámetros de Oxígeno Disuelto, pH, Nitratos, Sólidos Totales Disueltos, Turbidez y Temperatura a partir de muestras de agua. Mediante estos datos y la información espectral de imágenes del satélite Landsat 5 se evaluaron 30 modelos de regresión lineal de los cuales, la turbidez obtuvo el mejor ajuste. Las regiones del espectro $0,52-0,6 \mu \mathrm{m}$ y $0,63-0,69$ $\mu \mathrm{m}$, aportados por la variable predictora, se mostraron como los rangos de mayor correlación con los valores de turbidez. El modelo empleado para representar la turbidez espacialmente distribuida muestra que la presa la Boquilla obtiene los valores más altos, relacionados con la suspensión de sedimentos aportados por cauces efímeros a lo largo de todo el embalse.
\end{abstract}

Palabras clave: Aguas interiores; Contaminación hídrica; Eutrofización; Teledetección, Distribución espacial de la turbidez.

\begin{abstract}
The Basin of Conchos River, located in the State of Chihuahua (Mexico), has suffered a marked deterioration due to the development of human activities. The urban population growth, industrialization, and agriculture have significantly degraded water resources of this basin. To examine the quality of its waters, the reservoirs of Las Vírgenes dam, the Colina lake, and La Boquilla dam have been analyzed, determining the parameters of dissolved oxygen, $\mathrm{pH}$, nitrates, total dissolved solids, turbidity and temperature from water samples. Using these data and the spectral information of Landsat 5 satellite images, 30 linear regression models were evaluated; from these models, turbidity obtained the best match. The regions of spectrum $0.52-0.6 \mu \mathrm{m}$ and $0.63-0.69 \mu \mathrm{m}$, provided by the predictor variable, appeared as the ranges of higher correlation with the values of turbidity. The model used to represent the turbidity spatially distributed shows that La Boquilla dam gets the highest values related to the suspension of sediments provided by ephemeral channels throughout the reservoir.
\end{abstract}

Keywords: Inland waters; water pollution; eutrophication; Remote sensing, spatial distribution of turbidity.

5 Universidad Politécnica de Gómez Palacio (UPGP). El Vergel, Gómez Palacio, Durango, México. C.P. 35120. Correo electrónico: fabisegovia92@gmail.com

6 Doctor en Biología. Centro de Edafología y Biología Aplicada del Segura - Consejo Superior de Investigaciones Científicas (CEBAS-CSIC). Campus Universitario de Espinardo. Espinardo. Murcia, España. CP.30100. Correo electrónico: jalarcon@cebas.csic.es 
Jesús Amado-Alvarez, Pedro Pérez-Cutillas, Luis Carlos Alatorre-Cejudo, Orlando Ramirez-Valle, Elsa Fabiola Segovia Ortega, Juan José Alarcón-Cabañero. Análisis multiespectral para la estimación de la turbidez como indicador de la calidad del agua en embalses del estado de Chihuahua, México

\section{Introducción}

El estado de Chihuahua, ubicado al norte de México, representa más del 12\% de la superficie del país. Sus ecosistemas están formados, principalmente por pastizales, matorrales y desiertos, que ocupan gran parte del territorio (Comisión Nacional para el Conocimiento y Uso de la Biodiversidad [CONABIO], 2014). La actual industria agroalimentaria que sustenta gran parte de la economía del estado, se inició en los comienzos del siglo pasado con la puesta en marcha de ambiciosos planes de irrigación que modificaron la fisionomía de los amplios valles de la región. Entre estos desarrollos se encontraba la construcción de importantes infraestructuras hídricas que facilitaron la creación de grandes áreas de regadío, entre ellas, el Sistema Nacional de Riego número cinco donde se originó la Ciudad de Delicias (Aboites-Aguilar, 2000).

El aumento de las actividades humanas, asociadas al crecimiento económico de la zona, ha provocado un notable deterioro en la cuenca del río Conchos. El desarrollo urbano y la industrialización han intervenido en los procesos naturales del ciclo hidrológico de manera cualitativa y cuantitativa, alterando no sólo las funciones de suministro hídrico, sino la calidad del agua disponible (McDonald et al., 2011). Los desechos generados por estas actividades humanas degradan de manera notable los recursos hídricos, y de la misma forma, el desarrollo de las actividades agrícolas afecta a la contaminación de los aguas subterráneas y superficiales (Amado Álvarez et al., 2016). La escasa percepción del ciclo integral del agua por parte de los productores agrícolas, con una deficiente racionalización y un uso excesivo de fertilizantes y pesticidas, incide todavía más en los procesos de degradación, así como efectos nocivos para la salud pública (MartínezValenzuela y Gómez-Arroyo 2007; Carbajal-López et al., 2016).

Los métodos utilizados para la evaluación de los parámetros de la calidad del agua se han basado habitualmente en mediciones tomadas en campo (Hakanson et al., 2005). Con estos procedimientos se pueden proporcionar medidas exactas, pero su obtención demanda numerosos recursos. Además, la imposibilidad de proporcionar una visión en tiempo real de la distribución espacial de las variables que se están examinando, no permiten un control integral del estado del agua (Brivio et al., 2001).

Las técnicas de teledetección han demostrado su utilidad para proporcionar medios adecuados en la estimación de algunos de los parámetros 
Jesús Amado-Alvarez, Pedro Pérez-Cutillas, Luis Carlos Alatorre-Cejudo, Orlando Ramírez-Valle, Elsa Fabiola Segovia Ortega, Juan José Alarcón-Cabañero. Multispectral analysis to estimate the turbidity as an indicator of the quality of water in reservoirs in Chihuahua State, Mexico

relacionados con índices de calidad del agua. El avance en el diseño de nuevos sensores satelitales ha incrementado considerablemente las resoluciones espaciales, espectrales y temporales, permitiendo una mejora en la captación de la superficie terrestre (Feyisa et al., 2014). Debido a la necesidad de una gran precisión en los estudios a escala local, se han desarrollado algunos de los sensores en plataformas espaciales como SeaWiFS, EO-1 / Hyperion, ALOS AVNOR-2, IKONOS, HICO, y Landsat-8, o sobre plataformas aerotransportadas como CASI, AISA, AVIRIS, HyMap (Gholizadeh et al., 2016). El avance actual en imágenes hiperespectrales, con la capacidad de registrar simultáneamente hasta 200 canales espectrales, son los más recomendables para la detección de parámetros hídricos (Olmanson et al., 2013; Chen, Xiao y Li, 2016),

Son numerosos los estudios en los que se han determinado parámetros relativos a la calidad del agua en superficies marinas, como la clorofila, fitoplancton, materia orgánica disuelta, sólidos disueltos en suspensión o turbidez. Por lo que, la utilización de rangos espectrales desde el visible al infrarrojo cercano, información donde gran parte la energía es absorbida, han demostrado su utilidad para determinar datos sobre la calidad del agua (Giardiano et al., 2001; Kloiber et al., 2000; Bustamante et al., 2009; Chen et al., 2009; Fichot et al., 2016). Otros trabajos recientes, se centran en analizar mediante técnicas de teledetección parámetros de la calidad del agua en aguas interiores. Estos ambientes se caracterizan por su complejidad, en los que intervienen diversos e importantes procesos como la erosión, transporte de sedimentos y deposición en todas las cuencas hidrográficas, sedimentación de los embalses y contaminación del agua (Robert et al., 2016). La interacción de estos procesos hace complicada la obtención de modelos generales que puedan aplicarse en cualquier ambiente, y en la mayor parte de los casos la correlación de las propiedades físicoquímicas del agua a través de la información multiespectral solo se puede determinar de manera indirecta (Potes et al., 2011; Hansen et al., 2015)

La turbidez es una propiedad óptica de los cuerpos de agua, que se puede medir a través de la cantidad de luz dispersada y absorbida por las partículas en una columna de agua (Michaud, 1991), proporcionando unas características físicas que pueden ser captadas por los sensores a través de la radiación reflejada en distintas longitudes de onda. Además, la turbidez puede inducir a cambios en la estructura térmica vertical del lago, 
Jesús Amado-Alvarez, Pedro Pérez-Cutillas, Luis Carlos Alatorre-Cejudo, Orlando Ramirez-Valle, Elsa Fabiola Segovia Ortega, Juan José Alarcón-Cabañero. Análisis multiespectral para la estimación de la turbidez como indicador de la calidad del agua en embalses del estado de Chihuahua, México

jugando un papel importante en la producción primaria autóctona (Friedl y Wuest, 2002), así como en el aumento de la temperatura de la superficie del agua (Zhou et al., 2016). Por lo tanto, el uso de datos satelitales para evaluar estas propiedades ópticas del agua se está incrementando, debido a que proporcionan información directa para la caracterización de embalses (Chen, Hu y Muller-Karger, 2006; Gitelson et al., 2008; Potes et al., 2012; Hou et al., 2017).

\section{Área de estudio}

Los embalses que se analizaron en este trabajo forman parte de la cuenca del río Conchos, localizada en el sur del Estado de Chihuahua (Figura 1), que ocupa el $26 \%$ de la superficie estatal, y una pequeña parte del norte del Estado de Durango (México). Las aguas de sus cauces provienen de las cumbres de la Sierra Tarahumara en la Sierra Madre Occidental y llegan hasta su confluencia con el río Bravo en el Desierto Chihuahuense, límite natural de la frontera con Estados Unidos. Los embalses se encuentran dentro de la Región Hidrológica 24 del río Bravo-Conchos, representando esta superficie el 14\% del área total de esta cuenca (Carreón et al., 2001).

El primero de ellos corresponde a la presa Francisco I Madero, denominada como la presa de Las Vírgenes, que hidrológicamente cierra la subcuenca del río San Pedro. Fue construida por la Comisión Nacional de Irrigación, de la entonces Secretaria de Recursos Hidráulicos [actualmente CONAGUA]. Su capacidad de almacenamiento se ha visto severamente afectada por el gran volumen de sedimentos generados por los procesos erosivos. Por ello, recientemente, fue necesario incrementar la altura de la presa para mantener su función. Construida con un uso principal de riego, la presa cuenta con una capacidad útil de $347,93 \mathrm{hm}^{3}$ (Estrada Gutiérrez, Silva Hidalgo, Villalbal, Astorga Bustillos y Franco Estrada, 2015). También se han analizado las aguas de la presa de la Boquilla, que recoge las aguas de drenaje de la subcuenca del Altos Cochos. Tiene una función principal de irrigación, presentando una capacidad útil de $2771,58 \mathrm{hm}^{3}$ (Estrada Gutiérrez et al., 2015), con una cuenca de captación que abarca una superficie aproximada de $21.000 \mathrm{~km}^{2}$, siendo la presa más grande del estado de Chihuahua. Y finalmente, el lago Colina, que actúa como derivación de aguas para riego y regulación del flujo de salida de la presa de 
Jesús Amado-Alvarez, Pedro Pérez-Cutillas, Luis Carlos Alatorre-Cejudo, Orlando Ramírez-Valle, Elsa Fabiola Segovia Ortega, Juan José Alarcón-Cabañero. Multispectral analysis to estimate the turbidity as an indicator of the quality of water in reservoirs in Chihuahua State, Mexico

La Boquilla, situada aguas arriba, y actualmente, tiene una fuerte presión antrópica, debido a su uso vacacional y recreativo.

Figura 1. Localización de las cuencas hidrográficas del río Conchos y ubicación de los embalses, A) Presa las Vírgenes, B) Lago Colina y C) Presa la Boquilla.

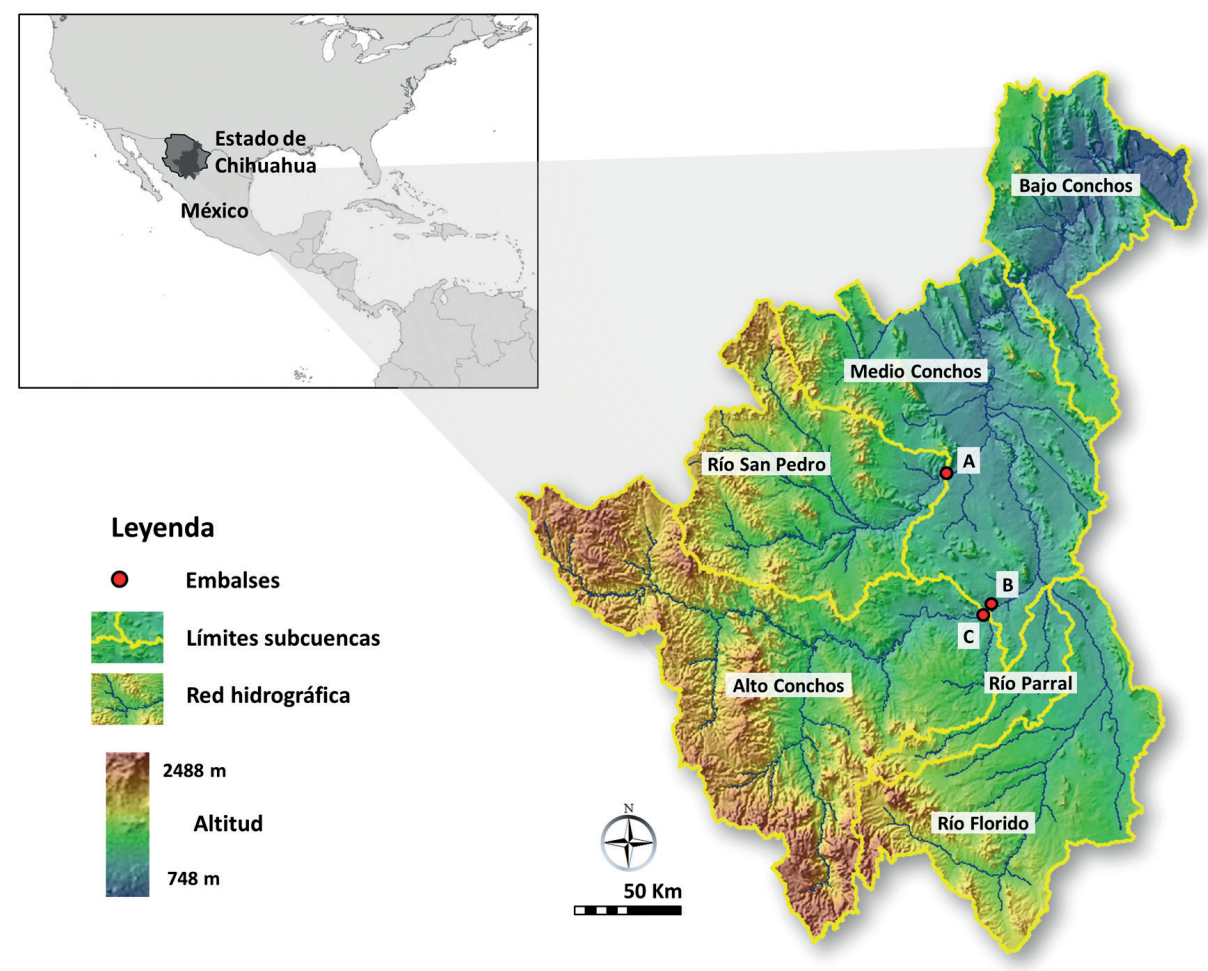

Fuente: Elaboración propia.

Estas infraestructuras hídricas son vitales para el Estado de Chihuahua, ya que abastecen a más de 100000 ha de riego (Aboites-Aguilar, 2002), además, de aportar un caudal continuo que permita cumplir con los compromisos del Tratado de Aguas de 1944 entre México y los Estados Unidos (Comisión Internacional de Límites y Aguas [CILA], 1944). La presión demográfica de la cuenca es considerable, albergando un millón y medio de personas, que representa el $42 \%$ de la población total del estado, 
y que en mayor parte se encuentran en el tramo intermedio de la cuenca (Instituto Nacional de Estadística y Geografía [INEGI], 2015).

Ambientalmente, la parte de cabecera, superficie que actúa como área receptora de estos embalses, presenta un dominio climático templado con estación húmeda durante el verano, proporcionando unos valores de precipitación medios de $900 \mathrm{~mm}$ anuales y una temperatura media anual entre $9-10{ }^{\circ} \mathrm{C}$. Valores que cambian en la parte central donde se ubican los embalses, con una precipitación media de $390 \mathrm{~mm}$ y temperaturas medias anuales que se elevan hasta los $19-20^{\circ} \mathrm{C}$ (Reyes-Gómez et al., 2006), lo que muestra la existencia de una amplia diversidad de dominios climáticos a lo largo de toda la cuenca. En general, los suelos muestran bajos contenidos de materia orgánica y deficiencias nutricionales, siendo dominantes en esta parte de la cuenca los Regosoles, Calcisoles y Feozems (CONABIO, 2016).

\section{Objetivos}

El objetivo de este estudio se centró en analizar diversos parámetros hídricos para determinar el origen de los factores que han influido en el deterioro del agua de los embalses examinados, así como elaborar y aplicar un modelo empírico predictivo que permita evaluar la calidad del agua a través de la estimación de la turbidez y de imágenes del satélite Landsat 5. Resultados que pueden servir para mejorar el conocimiento de estos ecosistemas, así como la protección y el correcto aprovechamiento de estos recursos lacustres.

\section{Metodología}

\section{Evaluación de valores físico-químicos del agua}

La fecha de muestreo se planificó siguiendo el calendario orbital del satélite Landsat 5. A bordo de una embarcación durante el periodo del 21 al 23 de marzo del 2011, se obtuvieron 37 muestras de agua de los tres embalses en puntos previamente fijados, los cuales fueron ubicados in situ mediante un receptor GPS (Figura 2). En cada lugar de registro, se precisó la profundidad del embalse a través de una ecosonda.

Las muestras de agua sirvieron para determinar su calidad, evaluándose los parámetros de Turbidez por el método Nefelométrico, basado en una comparación instrumental de la intensidad de luz dispersada por una muestra 
Jesús Amado-Alvarez, Pedro Pérez-Cutillas, Luis Carlos Alatorre-Cejudo, Orlando Ramírez-Valle, Elsa Fabiola Segovia Ortega, Juan José Alarcón-Cabañero. Multispectral analysis to estimate the turbidity as an indicator of the quality of water in reservoirs in Chihuahua State, Mexico

patrón de referencia bajo las mismas condiciones en capsulas de $15 \mathrm{ml}$ (Termo, AQ5000); el pH a través de la determinación de la actividad de los iones Hidrogeno $(\mathrm{H}+)$ en la solución por medición potenciométrica, empleando un electrodo de vidrio, previa calibración del instrumento con soluciones estándar de $\mathrm{pH}$ (Hanna Instrument $\mathrm{pH} / \mathrm{CE} / \mathrm{TSD} / \mathrm{T}$ meter). Con este potenciómetro también se obtuvieron los valores de STD $(\mathrm{g} / \mathrm{L})$ y la Temperatura en ${ }^{\circ} \mathrm{C}$; el OD, en \% de saturación, medido con un oxímetro portátil (Hanna Instrument - HI 9146); los Nitratos $\left(\mathrm{NO}_{3}\right.$ ) se tomaron con un medidor portátil (HORBA modelo B-343), utilizando el método de lectura con electrodo de ion, expresados en mg/L (Amado Álvarez et al., 2016).

Figura 2. Localización de los puntos de muestreo en cada uno de los embalses en el área de estudio
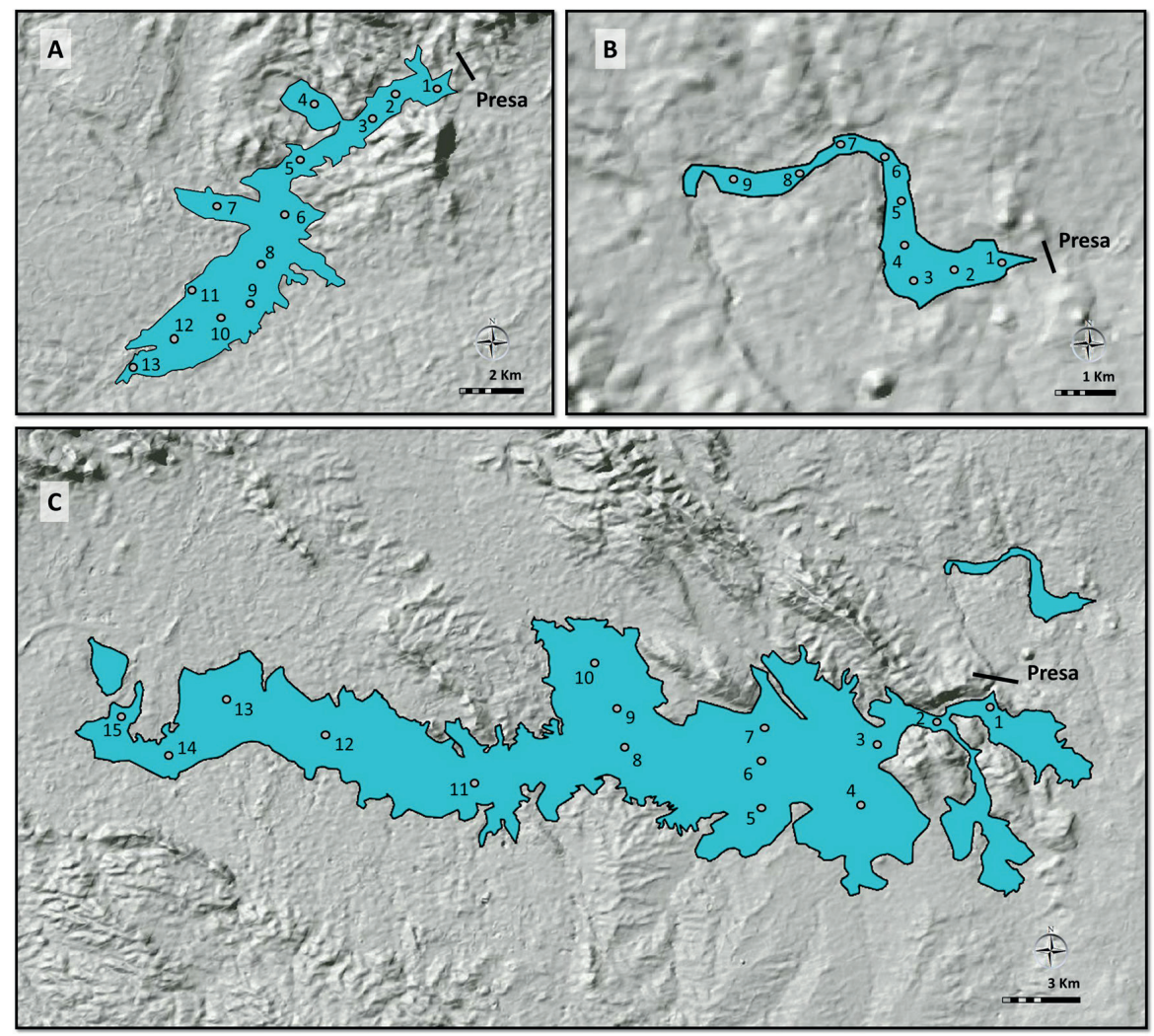

A) Presa las Vírgenes; B) Lago Colina; C) Presa Boquilla.

Fuente: Elaboración propia. 
Jesús Amado-Alvarez, Pedro Pérez-Cutillas, Luis Carlos Alatorre-Cejudo, Orlando Ramírez-Valle, Elsa Fabiola Segovia Ortega, Juan José Alarcón-Cabañero. Análisis multiespectral para la estimación de la turbidez como indicador de la calidad del agua en embalses del estado de Chihuahua, México

\section{Procesado de las imágenes de satélite}

En este trabajo se utilizaron dos escenas capturadas por el sensor Thematic Mapper (TM) del satélite Landsat 5, correspondientes al 22 de marzo de 2011. Este sensor puede captar varias regiones del espectro electromagnético a través de 7 bandas, mediante una resolución espacial de $30 \mathrm{~m}$ (Tabla 1).

Tabla 1. Características espectrales del sensor TM del satélite Landsat 5.

\begin{tabular}{|c|l|c|l|}
\hline Banda & \multicolumn{1}{|c|}{ Espectro } & Rango espectral $(\boldsymbol{\mu m})$ & \multicolumn{1}{|c|}{ Características } \\
\hline 1 & Azul (visible) & $0,45-0,515$ & $\begin{array}{l}\text { Máxima penetración en cuerpos de } \\
\text { agua }\end{array}$ \\
\hline 2 & Verde (visible) & $0,525-0,605$ & $\begin{array}{l}\text { Pico de reflectancia vegetación en el } \\
\text { rango visible }\end{array}$ \\
\hline 3 & Rojo (visible) & $0,63-0,69$ & Máxima absorción de la clorofila \\
\hline 4 & Infrarrojo cercano & $0,78-0,9$ & Determina el contenido de biomasa \\
\hline 5 & Infrarrojo medio 1 & $1,55-1,75$ & Indica humedad de suelo y vegetación \\
\hline 7 & Infrarrojo medio 2 & $2,09-2,35$ & Discriminación de minerales \\
\hline
\end{tabular}

Fuente: Elaboración propia.

Una de las principales limitaciones que se plantean con la utilización de imágenes de satélite es que se encuentran afectadas por una serie de perturbaciones radiométricas, como pueden ser la iluminación solar y las condiciones atmosféricas. En el caso de las imágenes de alta resolución espacial, como las de la familia de satélites Landsat, en las que la frecuencia temporal es baja, resulta necesario llevar a cabo procedimientos de transformación complejos. Para ello, se realizó la corrección geométrica de las imágenes mediante la utilización de una serie de puntos de control y el algoritmo desarrollado por Pala y Pons (1995), implementado en el software Miramon, en el que se tiene en cuenta la distorsión topográfica mediante la incorporación de un MDT. Por otra parte, también se trató el efecto atmosférico sobre la señal electromagnética, que fue corregida mediante el modelo de transferencia radiactiva 6S (Vermote et al., 1997).

\section{Análisis estadísticos}

En una primera fase, se trató de determinar las relaciones estadísticas entre los valores de los diferentes indicadores físico-químicos del agua obtenidos in situ y los niveles digitales (ND) asociados a la reflectancia a 
Jesús Amado-Alvarez, Pedro Pérez-Cutillas, Luis Carlos Alatorre-Cejudo, Orlando Ramírez-Valle, Elsa Fabiola Segovia Ortega, Juan José Alarcón-Cabañero. Multispectral analysis to estimate the turbidity as an indicator of the quality of water in reservoirs in Chihuahua State, Mexico

distintas longitudes de onda del espectro electromagnético, captadas por el satélite Landsat 5. Para ello, se aplicó el modelo de regresión lineal entre las variables obtenidas en los muestreos de agua y los ND de las bandas $1,2,3,4,5$ y 7 del sensor TM, que se utilizaron para medir la magnitud de la relación y su significancia estadística.

Las cuantificaciones obtenidas en las regresiones lineales realizadas sirvieron para ofrecer un total de corte, que se estableció en los valores superiores a 0,6 en el estadístico $\mathrm{R}^{2}$, lo que permitió seleccionar los indicadores físico-químicos válidos para una segunda fase de análisis. En esta parte del estudio estadístico se estableció un modelo predictivo con las variables obtenidas en las muestras de agua a partir de la reflectancia de todas las bandas del sensor TM, así como de los siguiente cocientes: TM1/TM2, TM2/TM3, TM3/TM4, y el cociente entre todas las bandas del visible y el infrarrojo cercano (TM1+TM2+TM3)/TM4 (Bustamante et al., 2009). Está información corresponde al promedio de los valores de reflectancia contenidos en una ventana de $3 \times 3$ píxeles para cada punto de muestreo, correspondiente a un área de $90 \times 90 \mathrm{~m}$, en cada una de las bandas del satélite Landsat TM.

Sobre estos datos se aplicó el coeficiente de correlación de Pearson, elaborado para variables cuantitativas, en las que se mide el grado de covariación entre distintas variables relacionadas linealmente. La asociación se basa en la posibilidad de encontrar variables fuertemente relacionadas, pero si no es de forma lineal, no se debe proceder a la utilización del test de correlación de Pearson. Este coeficiente de correlación estadístico es de fácil interpretación, oscila entre $-1 \mathrm{y}+1$, indicando que la magnitud de la relación viene especificada por el valor numérico del coeficiente, reflejando el signo la dirección del valor obtenido.

\section{Resultados}

\section{Análisis de los valores físico-químicos de las muestras de agua}

\section{a) Presa Francisco I. Madero}

Los resultados de los análisis físico-químicos de las muestras de agua tomadas en este embalse proporcionan en general unos niveles de aceptables de $\mathrm{OD}$, con una representación espacial relativamente homogénea, 
con valores porcentuales situados entre el 96,4 y $102,7 \%$ (Tabla 2). No obstante, se observa una tendencia descendente conforme nos alejamos de la presa en dirección a la cola del embalse (Figura 3).

Tabla 2. Valores promedio y desviación estándar de los parámetros físico-químicos obtenidos en los muestreos de agua en la presa de Las Vírgenes, en la Cuenca del Río San Pedro; y en el lago Colina y presa de la Boquilla, en la Cuenca del Alto Conchos.

\begin{tabular}{|l|c|c|c|c|c|c|c|}
\hline \multicolumn{1}{|c|}{ Muestras } & Embalse & OD & pH & STD & NO $_{3}$ & Temperatura & Turbidez \\
\hline Media & A & 99,2 & 8,39 & 0,17 & 9,4 & 18,4 & 14,01 \\
\hline Desv. Estandar & A & 2,1 & 0,61 & 0,01 & 1,5 & 0,8 & 6,00 \\
\hline Media & B & 100,2 & 7,11 & 0,16 & 11,9 & 16,6 & 19,60 \\
\hline Desv. Estandar & B & 5,5 & 0,43 & 0,00 & 4,6 & 1,0 & 1,74 \\
\hline Media & C & 94,8 & 8,28 & 0,14 & 9,3 & 18,4 & 10,82 \\
\hline Desv. Estandar & C & 7,0 & 0,44 & 0,01 & 1,3 & 1,4 & 5,92 \\
\hline
\end{tabular}

OD: Oxígeno Disuelto (\%), pH, STD: Sólidos Totales Disueltos (g/L), $\mathrm{NO}_{3}$ : Nitratos (mg/L), Temperatura $\left({ }^{\circ} \mathrm{C}\right)$, Turbidez (NTU). A: Las Vírgenes; B: Lago Colina; C: La Boquilla.

Fuente: Elaboración propia.

En el caso del $\mathrm{pH}$, se obtienen concentraciones de iones de hidrogeno que expresan una cierta alcalinidad del agua. Los STD también muestran una gran homogeneidad con valores medios a lo largo de todo el embalse de $0,17 \mathrm{~g} / \mathrm{L}$. Respecto a los niveles de nitratos, sí aparecen mayores cambios con valores elevados que pueden llegar a los $13 \mathrm{mg} / \mathrm{L}$, y con una tendencia clara que aumenta hacia el cierre de la presa. La temperatura del agua muestra una tendencia similar con valores de $16,9{ }^{\circ} \mathrm{C}$ en la cola del embalse, mientras que en la parte opuesta pueden llegar cerca de los 20 ${ }^{\circ} \mathrm{C}$. Por último, los valores de turbidez son los que más contraste aportan, describiendo una tendencia ascendente con datos que van desde los 9,73 hasta los 30,5 NTU en la zona de cola. 
Jesús Amado-Alvarez, Pedro Pérez-Cutillas, Luis Carlos Alatorre-Cejudo, Orlando Ramírez-Valle, Elsa Fabiola Segovia Ortega, Juan José Alarcón-Cabañero. Multispectral analysis to estimate the turbidity as an indicator of the quality of water in reservoirs in Chihuahua State, Mexico

Figura 3. Tendencia de los valores muestreados en la presa de Las

Vírgenes, en la Cuenca del Río San Pedro.
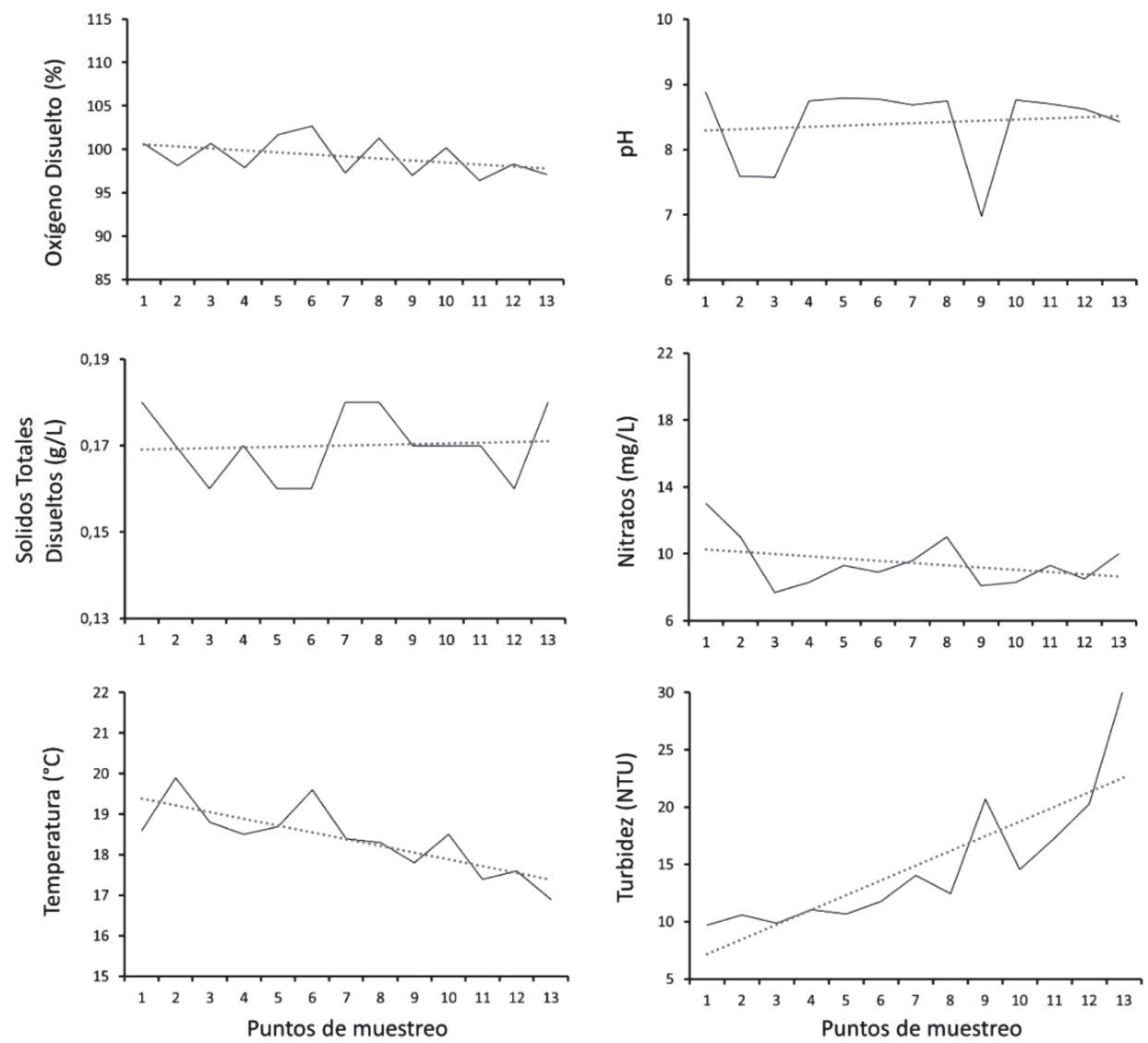

Distribución espacial, muestra 1 ubicada próxima a la presa, muestra 13 ubicada en la cola del embalse.

Fuente: Elaboración propia.

\section{b) Lago Colina}

Los análisis obtenidos en las muestras de agua del lago Colina proporcionan unos valores con tendencias similares a los del Embalse de Las Vírgenes (Figura 4). Pero la menor extensión de la lámina de agua proporciona resultados en general más homogéneos, a excepción del muestreo 1, que al ubicarse próximo a la presa se encuentra en la zona de agua más estancada, y esto explica sus valores diferentes al resto. Respecto a las mediciones de los nitratos, llama la atención su elevada concentración, con 
Jesús Amado-Alvarez, Pedro Pérez-Cutillas, Luis Carlos Alatorre-Cejudo, Orlando Ramírez-Valle, Elsa Fabiola Segovia Ortega, Juan José Alarcón-Cabañero. Análisis multiespectral para la estimación de la turbidez como indicador de la calidad del agua en embalses del estado de Chihuahua, México

valores que van en aumento desde la parte final del embalse en dirección a la presa hasta registros que llegan a los $23 \mathrm{mg} / \mathrm{L}$ (Tabla 2). También la temperatura muestra valores diferentes, con mediciones superiores a los 2 ${ }^{\circ} \mathrm{C}$, aproximadamente, más baja que los otros dos embalses. En relación con los datos de turbidez, con valores que van desde los 17,4 a los 22,43 NTU, proporcionan los niveles medios más elevados de las tres reservas de agua $(19,6 \mathrm{NTU})$.

Figura 4. Tendencia de los valores muestreados en el Lago Colina, en la Cuenca del Alto Conchos.
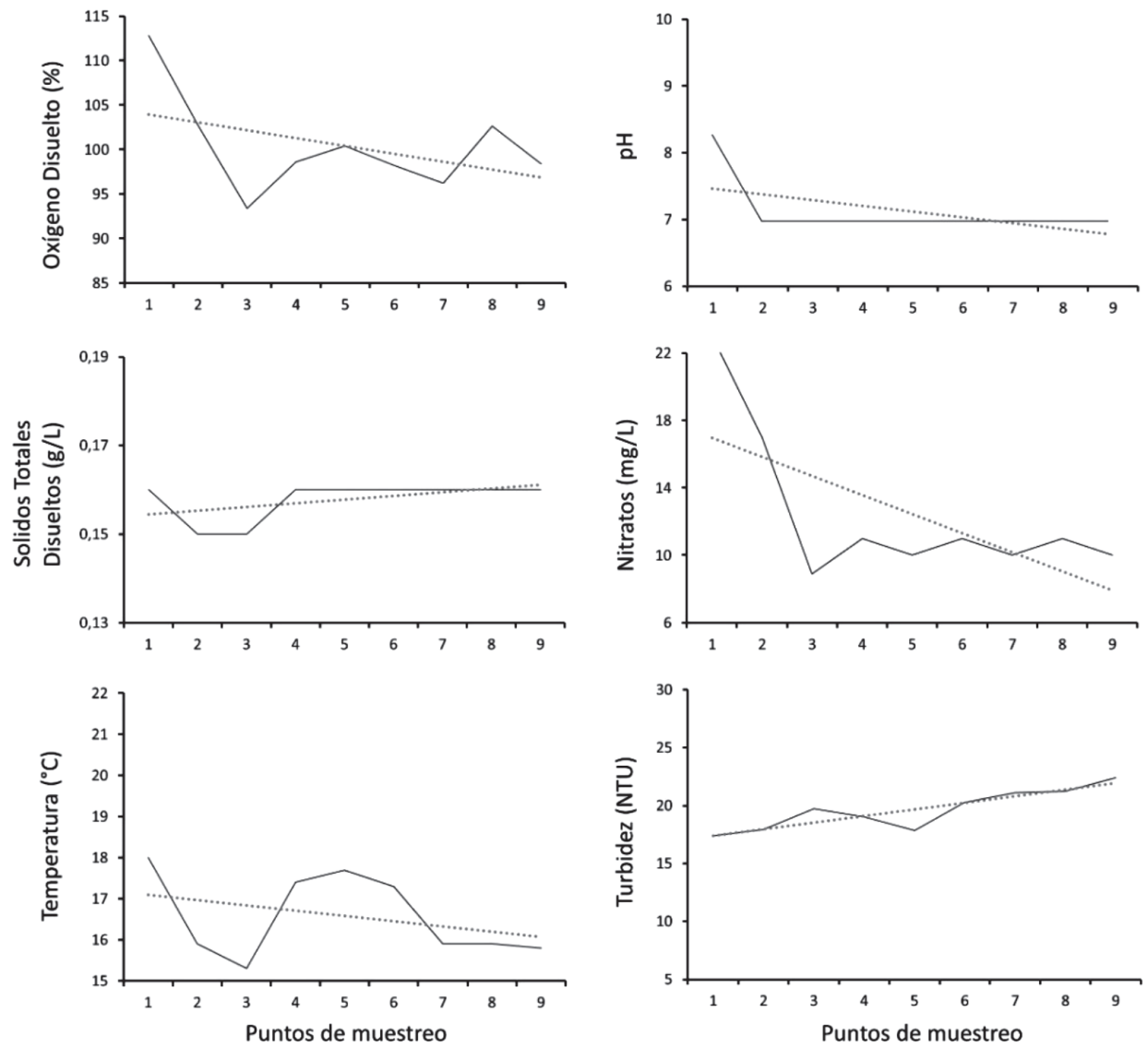

Distribución espacial, muestra 1 ubicada próxima a la presa, muestra 9 ubicada en la cola del embalse.

Fuente: Elaboración propia. 
Jesús Amado-Alvarez, Pedro Pérez-Cutillas, Luis Carlos Alatorre-Cejudo, Orlando Ramírez-Valle, Elsa Fabiola Segovia Ortega, Juan José Alarcón-Cabañero. Multispectral analysis to estimate the turbidity as an indicator of the quality of water in reservoirs in Chihuahua State, Mexico

\section{c) Presa la Boquilla}

Al igual que en el resto de embalses muestreados, el OD encontrado en el embalse de la Boquilla presenta valores homogéneos con datos que muestran un grado aceptable (media: 94,7) (Tabla 2). El nivel de $\mathrm{pH}$ encontrado en la mayoría de las muestras determina que las reservas de agua son alcalinas con datos máximos de 8,57 , mostrando una tendencia descendente hacia el final del embalse (Figura 5).

Figura 5. Tendencia de los valores muestreados en la presa de la Boquilla, en la Cuenca del Alto Conchos.
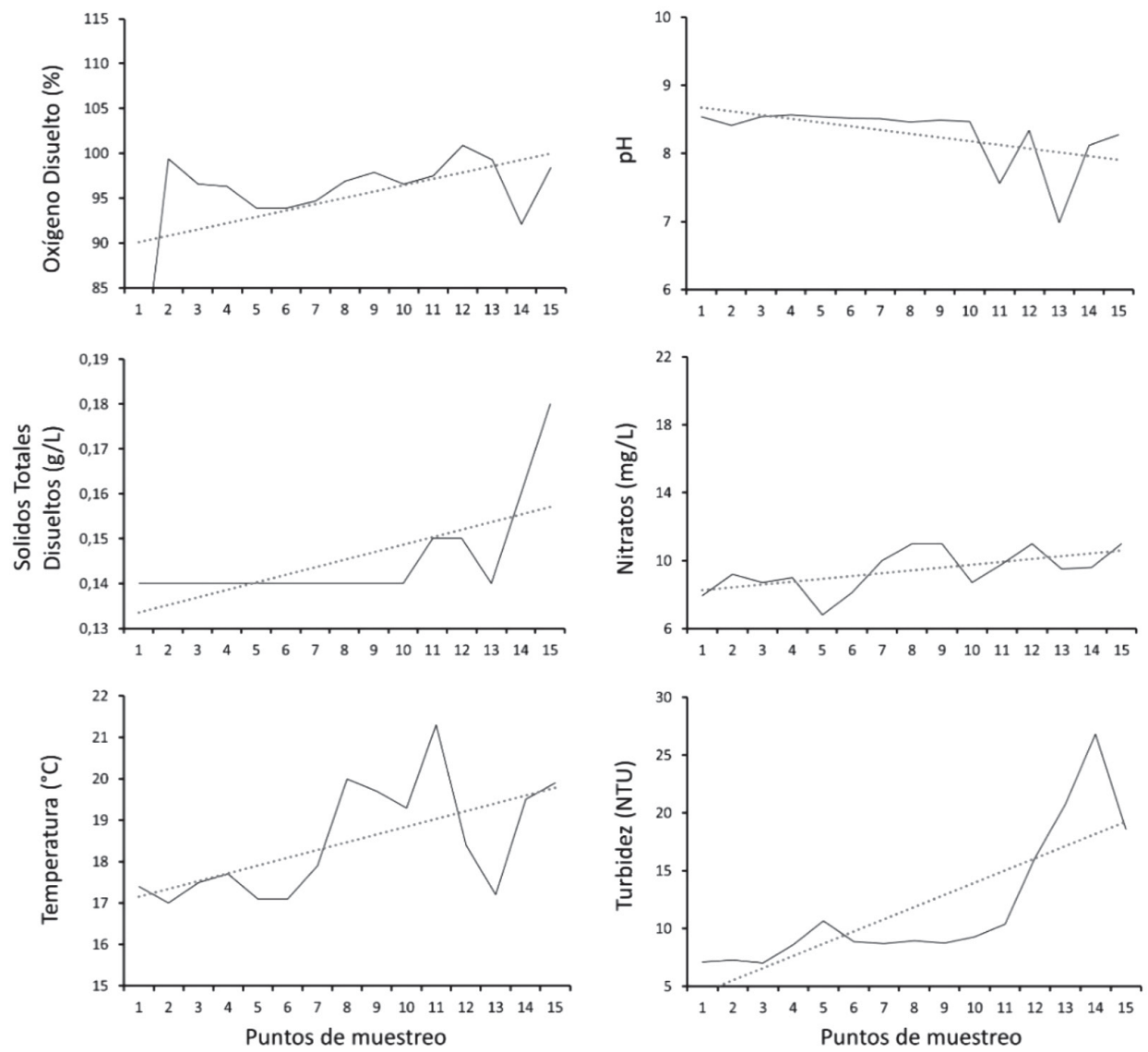

Distribución espacial, muestra 1 ubicada próxima a la presa, muestra 15 ubicada en la cola del embalse.

Fuente: Elaboración propia. 
Los STD obtenidos con valores medios de $0,144 \mathrm{~g} / \mathrm{L}$ se presentan más bajos, aunque con tendencia similar a los encontrados en el embalse de Las Vírgenes. Dirección que no siguen los resultados de los niveles de nitratos, en los que los valores más bajos $(7,93 \mathrm{mg} / \mathrm{L})$ se encuentran en el cierre de la presa, llegando a los $11 \mathrm{mg} / \mathrm{L}$ en la parte final del embalse. La temperatura muestra distintos valores a lo largo de todo el embalse, pero con temperatura media de $18,4^{\circ} \mathrm{C}$, que se asemeja a los resultados obtenidos en el embalse Las Vírgenes. Los datos de turbidez obtenidos muestran una clara tendencia de aumento conforme nos aproximamos a la parte final del embalse con valores máximos 26,83 NTU, pero en conjunto nos ofrece unos valores medios de 10,8 NTU, presentando los niveles de turbidez más bajos de los embalses estudiados.

\section{Análisis de la información espectral}

Índices de correlación de los parámetros de calidad del agua y la información espectral

Se evaluaron 30 modelos de regresión lineal a través de 5 de los pa-

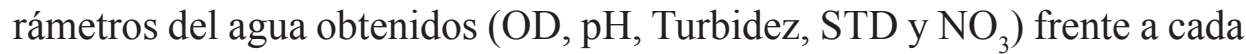
una de las bandas del satélite, con la información espectral como variable predictora. De las cuales, solo la turbidez obtuvo un ajuste superior al corte seleccionado, mostrando un valor de $\mathrm{R}^{2}$ de 0,68 .

En la segunda fase de análisis, se evaluó el coeficiente de correlación de Pearson, para establecer el grado de correlación entre los valores de turbidez y reflectancia para cada una de las bandas TM1-5 y TM7, los cocientes entre bandas TM1/TM2, TM2/TM3, TM3/TM4, y el cociente entre las bandas del visible y el infrarrojo cercano, (TM1+TM2+TM3)/TM4 (Vis NIR). Los resultados demostraron que el cociente entre las bandas TM2/ TM3 y la Turbidez presentaban el mejor grado de relación, con un coeficiente de -0.80 y una significación estadística bilateral por debajo de 0,01 (Tabla 3). También se observaron buenos ajustes para las bandas TM2, TM3 y TM4, con valores próximos a 0,7 . 
Tabla 3. Resultado de la correlación bivariada del coeficiente de Pearson entre los valores de turbidez y reflectancia las bandas del satélite Landsat 5.

\begin{tabular}{|c|c|c|c|c|c|c|c|c|c|c|}
\hline Turbidez & TM1 & TM2 & TM3 & TM4 & TM5 & TM7 & TM1/TM2 & TM2/TM3 & TM3/TM4 & VIS_NIR \\
\hline Coef. Pearson & 0,56 & 0,70 & 0,69 & 0,67 & 0,52 & 0,38 & $-0,18$ & $\mathbf{- 0 , 8 0}$ & 0,17 & $-0,40$ \\
\hline Sig. (bilateral) & 0,05 & 0,00 & 0,00 & 0,00 & 0,00 & 0,02 & 0,28 & $\mathbf{0 , 0 0}$ & 0,30 & 0,06 \\
\hline
\end{tabular}

Fuente: Elaboración propia.

\section{Aplicación del modelo predictivo de la turbidez}

Seleccionadas las variables Turbidez y cociente de las bandas TM2/ TM3 como las variables de mayor ajuste, el siguiente paso fue la obtención del modelo predictivo de la Turbidez mediante la información espectral, como aproximación más fiable de la estimación del estado del agua en los embalses estudiados.

La aplicación del modelo en cada uno de los embalses permitió obtener una distribución espacial de la turbidez. Los valores estimados para la Presa las Vírgenes se encontraron en un rango de 9,24 a los 34,27 NTU, mostrando los datos de turbidez más elevados de los tres embalses (Figura 6A). El lago Colina, en cambio, presenta los niveles de turbidez más bajos, con un rango que va desde los 13,89 a los 24,38 NTU. La distribución a lo largo del embalse de los valores muestra una clara gradación, aunque se observa una elevada heterogeneidad espacial (Figura 6B). La presa Boquilla muestra los valores más bajos, con datos que van desde los 6,21 a los 29,02 NTU. La representación espacial de la turbidez difiere del resto de embalses, mostrando valores en los que se observa una mayor turbidez en la parte de entrada al embalse, así como en los márgenes laterales (Figura 6C).

Figura 6. Análisis de distribución espacial de la turbidez del agua. 
Jesús Amado-Alvarez, Pedro Pérez-Cutillas, Luis Carlos Alatorre-Cejudo, Orlando Ramírez-Valle, Elsa Fabiola Segovia Ortega, Juan José Alarcón-Cabañero. Análisis multiespectral para la estimación de la turbidez como indicador de la calidad del agua en embalses del estado de Chihuahua, México
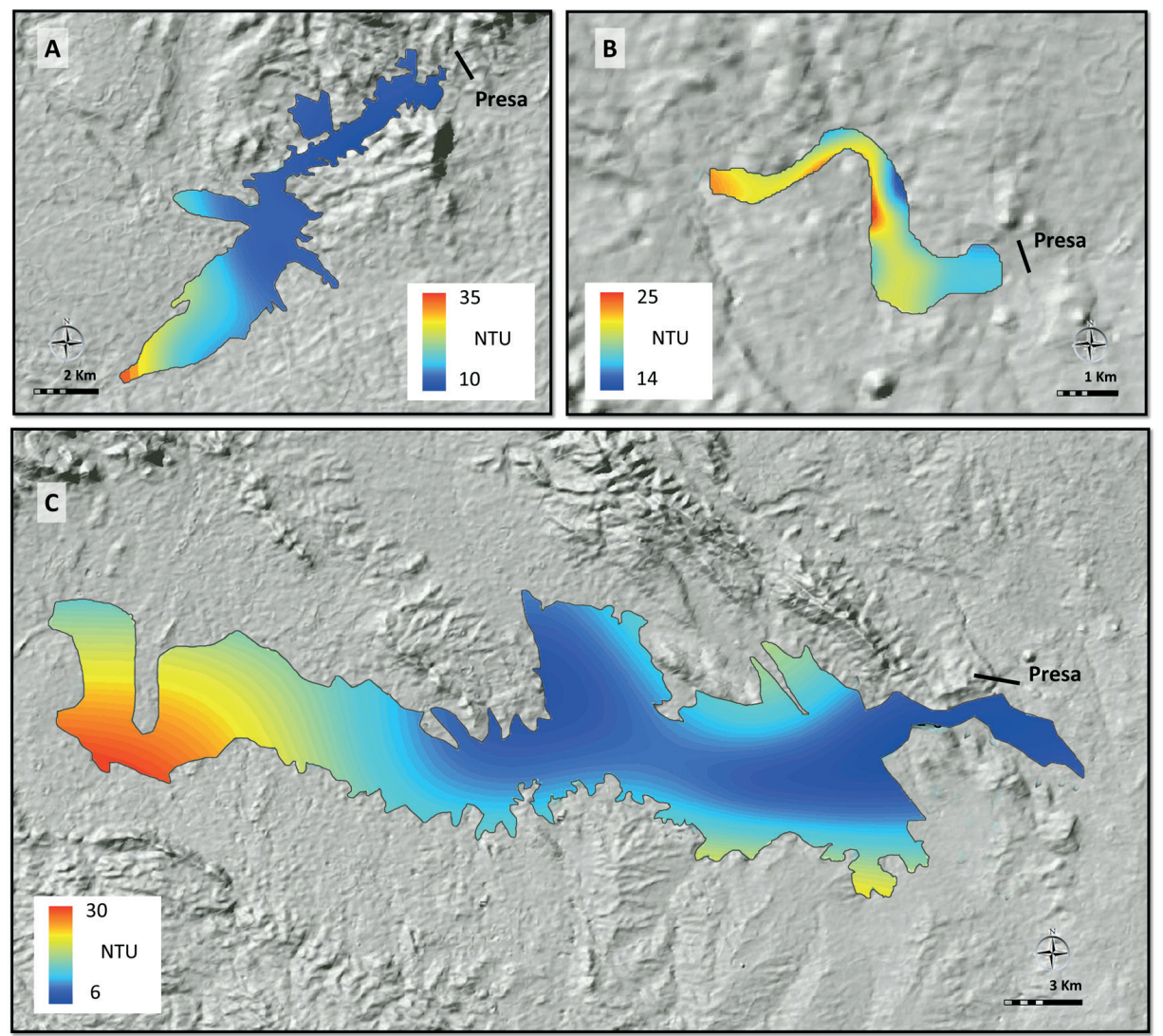

Turbidez (NTU) del agua en los tres embalses obtenida del modelo predictivo del cociente de las bandas TM2/TM3: A) Presa las Vírgenes; B) Lago Colina C) Presa Boquilla.

Fuente: Elaboración propia.

\section{Discusión}

Los resultados de los análisis de los valores físico-químicos de las muestras de agua en los tres embalses estudiados, determinan que la calidad del agua en general no presenta parámetros óptimos. Respecto al OD, que es uno de los indicadores más importantes de calidad del agua, se obtienen en los tres embalses unos valores medios aceptables con datos, que en el peor de los casos (en el embalse de La Boquilla) no superan la concentración de $9,4 \mathrm{mg} / \mathrm{L}$ o lo que es lo mismo un $94 \%$ de oxígeno disuelto. En agua dulce, el oxígeno disuelto no debería bajar del $80 \%$ de saturación, para poder mantener un cierto nivel de diversidad de biota 
Jesús Amado-Alvarez, Pedro Pérez-Cutillas, Luis Carlos Alatorre-Cejudo, Orlando Ramírez-Valle, Elsa Fabiola Segovia Ortega, Juan José Alarcón-Cabañero. Multispectral analysis to estimate the turbidity as an indicator of the quality of water in reservoirs in Chihuahua State, Mexico

(Ramos, Sepúlveda y Villalobos, 2003), siendo al menos la concentración de OD superior a $5 \mathrm{mg} / \mathrm{L}$ (50\% de saturación) para poder permitir la vida acuática (Calvo, Mora y Molina, 2007).

El valor del $\mathrm{pH}$ en el agua se presenta como una de las principales variables químicas, que permiten conocer el estado de la calidad hídrica. De igual forma, puede expresar particularidades de la litología y los cambios de las coberturas del suelo en las cuencas de drenaje, así como el desarrollo de la actividad biológica de estos embalses. (Tilman et al., 1982). En las mediciones, los resultados de $\mathrm{pH}$ se muestran similares, con niveles que señalan una tendencia alcalina $(\bar{X}: 8,2$ de $\mathrm{pH})$ en los dos embalses de mayor dimensión, relacionados con la tipología de suelo aportados por los sedimentos, producto de la erosión, deforestación y sobrepastoreo que sufre la zona de estudio (Amado Álvarez y Ortiz Franco, 2001). Solo el lago Colina, de menor dimensión, se acerca al valor de equilibrio ( $\bar{X}: 7,1 \mathrm{de} \mathrm{pH})$.

Las fuentes que originan los altos valores de STD en embalses están relacionados con la escorrentía procedente de la agricultura y los aportes de agua urbanos, así como la lixiviación de la contaminación del suelo y de las plantas de tratamiento industriales o de aguas residuales. Según Rawson (1951), las concentraciones de sólidos disueltos totales guardan una correlación positiva con la productividad y utilización de los lagos y embalses. Al mismo tiempo, los sólidos disueltos afectan la penetración de luz en la columna de agua y la absorción selectiva de los diferentes largos de onda que integran el espectro visible. En el caso de estudio estos niveles se mantienen por debajo de los índices permitidos NOM-OO1-ECO-1997 (Diario Oficial de la Federación [DOF], 1997a) con valores medios de 0,15 g/L.

Los sólidos disueltos pueden afectar de manera negativa a la calidad del agua, siendo los nitratos los elementos más habituales, asociados a la utilización de fertilizantes y pesticidas (Almasri y Kaluarachchi, 2004), así como a los efluentes de los grandes núcleos urbanos ubicados en estas zonas agrícolas (Chen et al., 2003). Las mayores tasas de nitratos disueltos en el agua se dan en el lago Colina $(11,8 \mathrm{mg} / \mathrm{L})$, sobrepasando las normas nacionales, donde el valor permisible en la concentración de $\mathrm{NO}^{3}$ es 10 partes por millón (ppm) o $10 \mathrm{mg} / \mathrm{L}$ (Secretaría de Economía, 1996). Aunque este lago tiene una ubicación distante y confinada de los valles agrícolas más importantes de esta zona de estudio, la concentración de estos elementos se debe en su mayor parte al uso recreativo que tiene este 
Jesús Amado-Alvarez, Pedro Pérez-Cutillas, Luis Carlos Alatorre-Cejudo, Orlando Ramirez-Valle, Elsa Fabiola Segovia Ortega, Juan José Alarcón-Cabañero. Análisis multiespectral para la estimación de la turbidez como indicador de la calidad del agua en embalses del estado de Chihuahua, México

ambiente lacustre, con el aporte de aguas residuales de las áreas urbanas que se encuentran en su entorno. El fosforo y los nitratos son alimentos esenciales para la vegetación, aunque en concentraciones altas puede provocar crecimiento excesivo de plantas y algas, lo que explica los niveles más altos de eutrofización de este lago.

La turbidez como indicador físico del agua, manifiesta limitaciones en el consumo humano, con un límite máximo permisible en México para el agua potable de 5 unidades nefelométricas de turbidez (NTU), expresadas en la NOM-127-SSA1-1994 (DOF, 1997b), siendo más restrictivos los valores propuestos por la Organización Mundial para la Salud, en la que no deben superar en ningún caso los 2 NTU. En los análisis realizados se observan valores altos de turbidez en los embalses, en concentraciones, que en el caso del lago Colina superan las 22 NTU. Los dos embalses, aun no siendo valores alarmantes, presentan unos resultados con datos medios de 14 y 10,8 mg/L, en Las Vírgenes y La Boquilla, respectivamente, con una turbidez debida a los sólidos y microorganismos en suspensión.

En conjunto, el análisis de estos parámetros físico-químicos se muestra como buenos indicadores de la calidad del agua, siendo la Turbidez junto al OD, las variables que más influyen en el deterioro de este recurso. Estudios realizados ponen de manifiesto que los procesos de degradación antrópicos son generalizados en gran parte desde la cuenca del río Conchos (CONABIO, 2016). Las principales causas de degradación están relacionadas esencialmente con procesos de deforestación y actividades agropecuarias, las cuales influyen de forma directa con el grado de Turbidez que presentan las aguas de los embalses estudiados. El aprovechamiento de los recursos forestales de la parte occidental de la cuenca es uno de los más explotados de todo el país, con un $24 \%$ de la producción nacional. Además, los incendios de los últimos 25 años han degradado más de 382000 ha, de las cuales 142000 han perdido por completo su capa superficial de suelo fértil (López, 2014). Por su parte, el sobrepastoreo se ha desarrollado a lo largo de toda la cuenca, con especial incidencia en la parte central. La excesiva carga ganadera del Estado de Chihuahua ha producido una alteración de ciclos biogeoquímicos y la pérdida de vegetación de hasta $80 \%$ en algunas partes de la región (Melgoza Castillo et al., 2014).

Estos registros demuestran que la erosión en estos ambientes semiáridos es un grave problema no solo por una fuerte amenaza para la 
Jesús Amado-Alvarez, Pedro Pérez-Cutillas, Luis Carlos Alatorre-Cejudo, Orlando Ramírez-Valle, Elsa Fabiola Segovia Ortega, Juan José Alarcón-Cabañero. Multispectral analysis to estimate the turbidity as an indicator of the quality of water in reservoirs in Chihuahua State, Mexico

biodiversidad regional, o por la pérdida de productividad agrícola, sino también por la colmatación de sedimentos de presas y embalses de agua. En estudios recientes se han estimado acumulaciones promedio de 260 $\mathrm{m}^{3} / \mathrm{Km}^{2} /$ año en la presa de la Boquilla y $254 \mathrm{~m}^{3} / \mathrm{Km}^{2} /$ año en la presa de Las Vírgenes, lo que representa pérdidas de la capacidad útil de sus embalsamientos del 9,88\% y 29,6\%, respectivamente (Estrada Gutiérrez et al., 2015). La demanda de un plan integral de gestión es necesaria para la sostenibilidad de estos recursos naturales, de lo contrario su impacto se irá incrementando, provocando altos costes económicos y ambientales (Raynal y Rodríguez-Pineda, 2008).

El fuerte incremento de los niveles de eutrofización ha quedado demostrado que está directamente asociado a fuentes antrópicas (Jack, 2006; von Gunten et al., 2009), convirtiéndose en uno de los problemas ambientales más importantes de lagos y embalses. La existencia de fertilizantes como el nitrógeno o fosforo utilizados en la agricultura, combinado con procesos erosivos que arrastran los nutrientes del suelo hacía estas reservas de aguas, elevan su contaminación y aceleran el desarrollo natural de la eutrofización. En las fases iniciales de trofización hídrica se comienza a alterar la diversidad biológica, provocando un aumento de los niveles de turbidez debido a la aparición de cianobacterias y macrófitos en el agua (Camargo y Alonso, 2007). La consecuencia directa es la disminución en la producción de oxígeno libre por la imposibilidad de llevar a cabo la fotosíntesis en las zonas más profundas, y de manera simultánea se produce un aumento de la actividad metabólica consumidora de oxígeno de los organismos descomponedores, que empiezan a recibir excedentes de materia orgánica generados en la superficie (Moreno et al., 2010).

Los efectos generados por la eutrofización son fácilmente apreciables por la proliferación de algas y el deterioro del agua, pero está ligado a procesos complejos, que en la mayoría de los casos ofrece dificultades de cuantificación. Desde el punto de vista de la teledetección, se han publicado trabajos realizados para la determinación de las características físicoquímicas relacionadas con índices de calidad del agua en lagos y embalses (Potes et al., 2011; Hansen et al., 2015), referidos a la elaboración de modelos predictivos de la clorofila, como factor principal de la existencia de biota acuática. Más escasos son los estudios recientes relacionados con la turbidez en estos ambientes. Los resultados que ofrecen son diversos, 
Jesús Amado-Alvarez, Pedro Pérez-Cutillas, Luis Carlos Alatorre-Cejudo, Orlando Ramirez-Valle, Elsa Fabiola Segovia Ortega, Juan José Alarcón-Cabañero. Análisis multiespectral para la estimación de la turbidez como indicador de la calidad del agua en embalses del estado de Chihuahua, México

mostrando modelos aplicados a distintos rangos espectrales, indicando la complejidad de estas estimaciones. En algunos casos el mejor ajuste de los modelos se basa en longitudes de onda en los rangos 0,63 - 0,69 $\mu \mathrm{m}$ y $0,75-0,90 \mu \mathrm{m}$, correspondientes al espectro rojo del visible y del infrarrojo cercano, respectivamente (Chien et al., 2016; Robert et al., 2016). La mejor predicción de estos valores espectrales está relacionada con los elevados índices de turbidez y la existencia de un alto grado de eutrofización, determinado en mayor medida por la respuesta fotosintética de la biota acuática (Kameyama et al., 2001; Vogt y Vogt, 2016).

Los resultados obtenidos en nuestro estudio muestran un modelo empírico de predicción de la turbidez del agua basado en las regiones del espectro $0,52-0,6 \mu \mathrm{m}$ y $0,63-0,69 \mu \mathrm{m}$. Una de las ventajas que muestra el modelo es su sencillez, aunque no queda exento de ciertas limitaciones en la estimación de este factor, que se hace mucho más fácil cuando las condiciones de profundidad del agua y la vegetación no interfieren, permitiendo llegar a distinguir aguas con una baja condición de turbidez. La determinación de la turbidez en estos rangos espectrales está asociada a la escasa presencia de algas, siendo provocada por la existencia de partículas en suspensión provenientes de los arrastres de solidos por erosión (Kameyama et al., 2001). En este sentido, el trabajo realizado por Potes et al. (2012) muestra unos valores similares de turbidez que fueron altamente correlacionados con un índice elaborado con información espectral de longitudes de onda similares a las utilizadas en nuestro modelo.

Desde un punto de vista espacial, el análisis de los resultados en cada uno de los embalses permitió determinar la distribución espacial de la turbidez. Los valores para la presa las Vírgenes mostraron los datos de turbidez más elevados, con las estimaciones de mayor intensidad localizadas en la parte final del embalse, que corresponde con el área de recepción del cauce. Estos niveles de turbidez están asociados al incremento de sedimentos en suspensión por procesos de erosión, que son recogidos en el embalse provocando importantes acumulaciones (Estrada Gutiérrez et al., 2015). El efecto del aporte de sedimentos también se presenta en la presa Boquilla, a pesar de mostrar los valores más bajos de NTU. La disposición espacial de la turbidez es distinta a la presa las Vírgenes, mostrando elevados valores tanto en la entrada del río Conchos al embalse como en los márgenes laterales, debido al aporte de sedimentos por tributarios de 
Jesús Amado-Alvarez, Pedro Pérez-Cutillas, Luis Carlos Alatorre-Cejudo, Orlando Ramírez-Valle, Elsa Fabiola Segovia Ortega, Juan José Alarcón-Cabañero. Multispectral analysis to estimate the turbidity as an indicator of the quality of water in reservoirs in Chihuahua State, Mexico

régimen intermitente. Por último, el lago Colina presenta los niveles de turbidez más bajos, con valores máximos que no superan los 25 NTU. La distribución a lo largo del embalse muestra una clara gradación desde la parte final (con valores más altos) hasta la presa (con valores bajos). Aunque se observa una elevada heterogeneidad espacial, debido en primer lugar a su fisionomía, ya que de los tres embalses es el más pequeño y de menor profundidad; $y$, por otra parte, el uso recreativo al que está destinado, hace que los sedimentos en suspensión tengan una mayor dispersión.

\section{Conclusiones}

Los valores obtenidos en los análisis de agua de los embalses estudiados determinan que las variables que más influyen en el detrimento de la calidad hídrica son la turbidez, el $\mathrm{pH}$ y el $\mathrm{NO}_{3}$. La degradación de estas aguas está relacionada con los procesos de deforestación, el incremento de la actividad agrícola y el desarrollo urbano que ha experimentado el entorno de estas presas. Por ello, es fundamental la identificación de las causas que originan los procesos de erosión, así como el emprendimiento de actividades de restauración y conservación de suelos de manera integral en toda la cuenca. También es importante un cambio en los manejos agrícolas, que por el efecto pernicioso del uso de productos agroquímicos y por los lixiviados tóxicos contaminan las aguas superficiales, al igual que la aplicación de mejoras en los sistemas de gestión integral en el tratamiento de aguas residuales urbanas.

Estos ambientes semiáridos son espacios muy sensibles y vulnerables a las variaciones provocadas por las actividades humanas. La escasa disponibilidad de agua unida a su degradación de forma natural o antrópica limitan todavía más su aprovechamiento, especialmente, para consumo humano. Por lo que, las técnicas de teledetección se presentan como instrumentos válidos para diagnosticar de manera ágil y con cierto grado de precisión algunos parámetros de calidad del agua como la turbidez, con una reducción importante de los análisis en laboratorio. A su vez, el tratamiento de imágenes de satélite puede ayudar a una mejor comprensión de estos ambientes acuáticos y limnológicos, así como a la prolongación de la vida útil de las infraestructuras de reservas hídricas.

En definitiva, este trabajo ha puesto de manifiesto la utilidad de estas herramientas para la monitorización espacial de los embalses localizados 
Jesús Amado-Alvarez, Pedro Pérez-Cutillas, Luis Carlos Alatorre-Cejudo, Orlando Ramirez-Valle, Elsa Fabiola Segovia Ortega, Juan José Alarcón-Cabañero. Análisis multiespectral para la estimación de la turbidez como indicador de la calidad del agua en embalses del estado de Chihuahua, México

en las cuencas hidrográficas de los ríos San Pedro y Conchos. La alta capacidad de adquisición de datos terrestres, así como la fiabilidad que aporta la información captada por estos sensores, reduciendo la subjetividad de las tomas de datos en campo, hace que esta sencilla metodología pueda ser extrapolada a otras áreas de características similares.

\section{Referencias}

Aboites-Aguilar, L. (2000). Demografía histórica y conflictos por el agua: Dos estudios sobre 40 kilómetros de historia del río San Pedro, Chihuahua. Ciesas.

Aboites-Aguilar, L. (2002). Hacia una historia del río Conchos. Ciesas, Cd. Juárez, Chihuahua.

Almasri, M.N. \& Kaluarachchi, J.J. (2004). Assessment and management of long-term nitrate pollution of ground water in agriculture-dominated watersheds. Journal of Hydrology, 295, 225-245. Recuperado de http://doi.org/10.1016/j.jhydrol.2004.03.013

Amado Álvarez, J.P. y Ortíz Franco, P. (2001). Consecuencia de la fertilización nitrogenada y fosfórica sobre la producción de avena irrigada con agua residual. Terra, 19, 175-182. Recuperado de https://chapingo.mx/terra/contenido/19/2/art175-182.pdf

Amado Álvarez, J.P., Pérez-Cutillas, P., Ramírez Valle, O. y Alarcón, J.J. (2016). Degradación de los recursos hídricos en un ambiente semiárido. Las lagunas de Bustillos y de Los Mexicanos (Chihuahua, México). Papeles de Geografía, 62, 107-118. Recuperado de http:// dx.doi.org/10.6018/geografia/2016/255811

Brivio P.A., Giardino, C. \& Zilioli, E. (2001). Validation of satellite data for quality assurance in lake monitoring applications. Sci Total Environ, 268, 3-13. Recuperado de http://doi.org/10.1016/ S0048-9697(00)00693-8

Bustamante, J., Pacios, F., Díaz-Delgado, R. y Aragonés, D. (2009). Predictive models of turbidity and water depth in the Doñana marshes using Landsat TM and ETM images. Journal of Environmental Management, 90, 2219-2225. http://doi.org/10.1016/j.jenvman.2007.08.021

Camargo, J.A. y Alonso, A. (2007). Contaminación por nitrógeno inorgánico en los ecosistemas acuáticos: problemas medioambientales, criterios de calidad del agua, e implicaciones del cambio climático. 
Jesús Amado-Alvarez, Pedro Pérez-Cutillas, Luis Carlos Alatorre-Cejudo, Orlando Ramírez-Valle, Elsa Fabiola Segovia Ortega, Juan José Alarcón-Cabañero. Multispectral analysis to estimate the turbidity as an indicator of the quality of water in reservoirs in Chihuahua State, Mexico

Ecosistemas, 16, 98-110. Recuperado de www.revistaecosistemas. net/index.php/ecosistemas/article/download/457/438

Calvo B.; Mora, G. y Molina, J. (2007). Evaluación y clasificación preliminar de la calidad del agua de la cuenca del río Tárcoles y el Reventazón Parte I: Análisis de la contaminación de cuatro ríos del área metropolitana. Tecnología en Marcha 20. Recuperado de http://revistas.tec.ac.cr/index.php/tec_marcha/article/view/46

Carbajal-López, Y., Gómez-Arroyo, S., Villalobos-Pietrini, R., Calderón-Segura, M.E. y Martínez-Arroyo, A. (2016). Biomonitoring of agricultural workers exposed to pesticide mixtures in Guerrero state, Mexico, with comet assay and micronucleus test. Environmental Science and Pollution Research, 23, 2513-2520. Recuperado de https://doi.org/10.1007/s11356-015-5474-7

Carreón, H.E., Pinedo, A. y Lafón, T. (2001). Aplicación de tecnología geoespacial en el estudio de cuencas: caso rio Conchos. XI Congreso Nacional de Irrigación. Simposio 5, 10-15. Manejo Integral de Cuencas. Guanajuato, Gto, México.

Chen, J., Tang, C., Shen, Y., Sakura, Y. \& Fukushima, Y. (2003). Nitrate pollution of groundwater in a wastewater irrigated field in Hebei Province, China. IAHS-AISH Publication, 285, 23-27. Recuperado de http://hydrologie.org/redbooks/a285/iahs_285_0023.pdf

Chen, Z., Hu, C., and Muller-Karger, F. (2006). Monitoring turbidity in Tampa Bay using MODIS/Aqua 250-m imagery. Remote Sens. Environ., 109, 207-220. Recuperado de http://doi.org/10.1016/j. rse.2006.12.019

Chen, S., Fang, L., Zhang, L. \& Huang, W. (2009). Remote sensing of turbidity in seawater intrusion reaches of Pearl River Estuary - A case study in Modaomen water way, China. Estuarine, Coastal and Shelf Science, 82, 119-127. Recuperado de http://doi.org/10.1016/j. ecss.2009.01.003

Chen, F., Xiao, D. \& Li, Z. (2016). Developing water quality retrieval models with in situ hyperspectral data in Poyang Lake, China. Geo-Spatial Information Science, 19, 255-266. Recuperado de http://dx.doi. org/10.1080/10095020.2016.1258201

Chien, W.H., Wang, T.S., Yeh, H.C. \& Hsieh, T.K. (2016). Study of NDVI Application on Turbidity in Reservoirs. J Indian Soc 
Jesús Amado-Alvarez, Pedro Pérez-Cutillas, Luis Carlos Alatorre-Cejudo, Orlando Ramirez-Valle, Elsa Fabiola Segovia Ortega, Juan José Alarcón-Cabañero. Análisis multiespectral para la estimación de la turbidez como indicador de la calidad del agua en embalses del estado de Chihuahua, México

Remote Sens, 44, 829-836. Recuperado de http://dx.doi.org/10.1007/ s12524-015-0533-6

Comisión Internacional de Límites y Aguas [CILA]. (1944). Tratado entre el gobierno de los Estados Unidos Mexicanos y el gobierno de los Estados Unidos de América de la distribución de las aguas internacionales de los ríos Colorado, Tijuana y Bravo, desde Fort Quitman, Texas, hasta el Golfo de México. Comisión Internacional de Límites y Aguas Entre México y los Estados Unidos Sección Mexicana, 28 p. Recuperado de http://www.sre.gob.mx/cila/

Comisión Nacional para el Conocimiento y Uso de la Biodiversidad [CONABIO]. (2014). La biodiversidad en Chihuahua: Estudio de Estado. México.

Comisión Nacional para el Conocimiento y Uso de la Biodiversidad [CONABIO]. (2016). Recuperado de: http://www.conabio.gob.mx/ informacion/gis/. Comisión intersecretarial del Gobierno de México. Diario Oficial de la Federación [DOF] (1997a). NOM-OO1-ECO-1997. México. 6 de enero de 1997.

Diario Oficial de la Federación [DOF] (1997b). NOM-127-SSA1-1994. México. 10 de enero de 1997.

Estrada Gutiérrez, G., Silva Hidalgo, H., Villalba1, M.L., Astorga Bustillos, F. y Franco Estrada, B. (2015). Tasa de acumulación de sedimentos en embalses del río Conchos, Chihuahua, México. 1er Congreso Iberoamericano sobre sedimentos y ecología Querétaro, Querétaro México.

Feyisa, G.L., Meilby, H., Fensholt, R. \& Proud, S.R. (2014). Automated Water Extraction Index: A new technique for surface water mapping using Landsat imagery. Remote Sensing of Environment, 140, 23-35. Recuperado de http://doi.org/10.1016/j.rse.2013.08.029

Fichot, C.G., Downing, B.D., Bergamaschi, B.A., Windham-Myers, L., Marvin-DiPasquale, M., Thompson, D.R. \& Gierach, M.M. (2016). High-Resolution Remote Sensing of Water Quality in the San Francisco Bay-Delta Estuary. Environmental Science \& Technology, 50, 573-583. Recuperado de http://doi.org/10.1021/acs.est.5b03518

Friedl, G. \& Wuest, A. (2002). Disrupting biogeochemical cycles. Consequences of damming. Aquat. Sci., 64, 55-65. Recuperado de http:// doi.org/10.1007/s00027-002-8054-0 
Jesús Amado-Alvarez, Pedro Pérez-Cutillas, Luis Carlos Alatorre-Cejudo, Orlando Ramírez-Valle, Elsa Fabiola Segovia Ortega, Juan José Alarcón-Cabañero. Multispectral analysis to estimate the turbidity as an indicator of the quality of water in reservoirs in Chihuahua State, Mexico

Gholizadeh, M.H., Melesse, A.M. \& Reddi, L. (2016). A Comprehensive Review on Water Quality Parameters Estimation Using Remote Sensing Techniques. Sensors, 16, 2-43. Recuperado de https://doi. org/10.3390/s16081298

Giardiano, C., Pepe, M., Brivio, P.A., Ghezzi, P. \& Zilioli, E. (2001). Detecting chlorophyll, secchi disk depth and surface temperature in a sub-alpine lake using Landsat imagery. Sci Total Environ, 268, 1929. Recuperado de http://doi.org/10.1016/S0048-9697(00)00692-6 Gitelson, A.A., Dall'Olmo, G., Moses, W., Rundquist, D.C., Barrow, T., Fisher, T. R., \& Holz, J. (2008). A simple semianalytical model for remote estimation of chlorophyll-a in turbid waters: Validation. $R e-$ mote Sens. Environ., 112, 3582-3593. Recuperado de http://doi. org/10.1016/j.rse.2008.04.015

Hakanson, L., Mikrenska, M., Petrov, K., \& Foster I. (2005). Suspend particulate matter (SPM) in rivers: empirical data and models. Ecological Modelling, 183, 251-267. Recuperado de http://doi.org/10.1016/j. ecolmodel.2004.07.030

Hansen, C.H., Williams, G.P., Adjei, Z., Barlow, A., Nelson, E.J. \& Miller, A.W. (2015). Reservoir water quality monitoring using remote sensing with seasonal models: case study of five central-Utah reservoirs. Lake and Reservoir Management, 31, 225-240. Recuperado de http://dx.doi.org/10.1080/10402381.2015.1065937

Hou, X., Feng, L., Duan, H., Chen, X., Sun, D. \& Shi, K. (2017). Fifteenyear monitoring of the turbidity dynamics in large lakes and reservoirs in the middle and lower basin of the Yangtze River, China. Remote Sensing of Environment, 190, 107-121. Recuperado de http:// doi.org/10.1016/j.rse.2016.12.006

Instituto Nacional de Estadística y Geografía [INEGI]. X.I.I. (2015). Censo General de población y Vivienda. Recuperado de http://www. beta.inegi.org.mx/temas/estructura/

Jack, B. (2006). Member state responsibilities concerning nitrate pollution and eutrophication: A role for the waste framework directive?: EC environmental law-agricultural pollution-eutrophication-urban waste water treatment directive-agricultural nitrates directive-waste framework directive-EIA directive-groundwater directive Commission of the European Communities v Kingdom of Spain, intervener. 
Jesús Amado-Alvarez, Pedro Pérez-Cutillas, Luis Carlos Alatorre-Cejudo, Orlando Ramirez-Valle, Elsa Fabiola Segovia Ortega, Juan José Alarcón-Cabañero. Análisis multiespectral para la estimación de la turbidez como indicador de la calidad del agua en embalses del estado de Chihuahua, México

Journal of Environmental Law, 18, 301-311. Recuperado de https:// papers.ssrn.com/sol3/papers.cfm?abstract id $=914764$

Kameyama, S., Yamagata, Y., Nakamura, F. \& Kaneko, M. (2001). Development of WTI and turbidity estimation model using SMA application to Kushiro Mire, eastern Hokkaido, Japan. Remote Sensing of Environment, 77, 1-9. Recuperado de http://doi.org/10.1016/ S0034-4257(01)00189-4

Kloiber, S.M., Anderle, T.H., Brezonik, P.L., Olmanson, L.G., Bauer, M.E. \& Brown, D.A. (2000). Trophic state assessment of lakes in the Twin Cities (Minnesota, USA) region by satellite imagery. Arch Hydrobiol Adv Limnol, 55, 137-151.

López, J. Z. (2014). Programa de manejo integral de la cuenca del río conchos. Primera edición, DR C Comisión Nacional para el Conocimiento y Uso de la Biodiversidad. Liga Periférico-Insurgentes Sur 4903 Parques del Pedregal.

Martínez-Valenzuela, C. y Gómez-Arroyo, S. (2007). Genotoxic risk in agricultural workers exposed to pesticides. Revista Internacional de Contaminación Ambiental, 23, 185-200. Recuperado de www.revistascca.unam.mx/rica/index.php/rica/article/download/21636/21636

McDonald, R.I., Douglas, I., Revenga, C., Hale, R., Grimm, N., Grönwall, J. \& Fekete, B. (2011). Global urban growth and the geography of water availability, quality, and delivery. Ambio, 40, 437-446. Recuperado de https://dx.doi.org/10.1007\%2Fs 13280-011-0152-6

Melgoza Castillo, A., Royo, M. y Ortega Ochoa, C. (2014). Sobrepastoreo, en: La biodiversidad en Chihuahua: Estudio de Estado. CONABIO. México, 228-230. Recuperado de http:/www.biodiversidad.gob.mx/ region/EEB/pdf/Chihuahua_Final_Web.pdf

Michaud, J. P. (1991). A citizen's guide to understanding and monitoring lakes and streams, Publ. \#94-149, Washington State Dept. of Ecology, Publications Office, Olympia, WA.,

Moreno, D.P., Quintero, J. y López, A. (2010). Métodos para identificar, diagnosticar y evaluar el grado de eutrofia. ContactoS, 78, 25-33. Recuperado de http:/www.izt.uam.mx/newpage/contactos/anterior/ n78ne/eutrofia2.pdf

Olmanson, L.G., Brezonik, P.L. \& Bauer, M.E. (2013). Airborne hyperspectral remote sensing to assess spatial distribution of water quality 
Jesús Amado-Alvarez, Pedro Pérez-Cutillas, Luis Carlos Alatorre-Cejudo, Orlando Ramírez-Valle, Elsa Fabiola Segovia Ortega, Juan José Alarcón-Cabañero. Multispectral analysis to estimate the turbidity as an indicator of the quality of water in reservoirs in Chihuahua State, Mexico

characteristics in large rivers: The Mississippi River and its tributaries in Minnesota. Remote Sensing of Environment, 130, 254-265. Recuperado de http://doi.org/10.1016/j.rse.2012.11.023

Palà, V. y Pons, X. (1995). Incorporation of relief into geometric corrections based on polynomials. Photogrammmetric Engineering and Remote Sensing, 61, 935-944.

Potes, M., Costa, M.J., da Silva, J.C.B., Silva, A.M. \& Morais, M. (2011). Remote sensing of water quality parameters over Alqueva, Reservoir in the south of Portugal. International Journal of Remote Sensing, 32, 3373-3388. Recuperado de http://dx.doi. org/10.1080/01431161003747513

Potes, M., Costa, M.J., \& Salgado, R. (2012). Satellite remote sensing of water turbidity in Alqueva reservoir and implications on lake mode1ling. Hydrol. Earth Syst. Sci., 16, 1623-1633. Recuperado de http:// dx.doi.org/10.5194/hess-16-1623-2012

Ramos, O.R., Sepúlveda, M.R. y Villalobos, M.F. (2003). Agua en el medio ambiente. Muestreo y análisis. Universidad Autónoma de Baja California. Ed. Plaza y Valdés, México.

Raynal, J.A. y Rodríguez-Pineda, J.A. (2008). Posibles escenarios del impacto del cambio climático en la cuenca del río Conchos, México. XX Congreso Nacional de Hidráulica, Toluca, Estado de México, México.

Rawson, D.S. (1951) The Total Mineral Content of Lake Waters. Ecology, 32, 669-672. Recuperado de http://doi.org/10.2307/1932733

Reyes-Gómez, V.M., Núñez-López, D., Muñoz-Robles, C.A., Gadsden, H., Rodríguez, J.A., López, M.A. y Hinojosa, O.R. (2006). Caractérisation de la sécheresse hydrologique dans le bassin versant Rio Conchos, Chihuahua, Mexique. Science et Changements Planétaires-Sécheresse, 17, 475-484. Recuperado de http://doi.org/10.1684/ sec.2006.0059

Robert, E., Grippa, M., Kergoat, L., Pinet, S., Gal, L., Cochonneau, G. \& Martinez, J.-M. (2016). Monitoring water turbidity and surface suspended sediment concentration of the Bagre Reservoir (Burkina Faso) using MODIS and field reflectance data. International Journal of Applied Earth Observation and Geoinformation, 52, 243-251. Recuperado de http://doi.org/10.1016/j.jag.2016.06.016 
Secretaría de Economía. (1996). Establecimiento de los límites máximos permisibles de contaminantes en las descargas de agua residuales en aguas y bienes nacionales. NOM-001-SEMARNAT-1996. Diario Oficial de la federación. 6 de enero de 1997. México.

Tilman, D.; Kilham, S. S. \& Kilham, P. (1982). Phytoplankton community ecology: The role of limiting nutrients. Ann. Rev. Ecol. Syst., 13, 349372. Recuperado de http://www.annualreviews.org/doi/abs/10.1146/ annurev.es.13.110182.002025

Vermote, E.F., Tanré, D., Deuzé, J.L., Herman, M. \& Morcrette, J.J. (1997). Second simulation of the satellite signal in the solar spectrum, 6s: an overview. IEEE Transactions on Geoscience and Remote Sensing, 35, 675-686. Recuperado de https://modis-atmos.gsfc.nasa.gov/ new_reference/data/papers/Vermote_et_al_B.1997.pdf

Vogt, M.C. \& Vogt, M.E (2016). Near-Remote Sensing of Water Turbidity Using Small Unmanned Aircraft Systems. Environmental Practice, 18, 18-31. Recuperado de http://www.tandfonline.com/doi/ abs/10.1017/S1466046615000459

Von Gunten, L., Grosjean, M., Eggenberger, U., Grob, P., Urrutia, R. \& Morales, A. (2009). Pollution and eutrophication history AD 18002005 as recorded in sediments from five lakes in Central Chile. Global and Planetary Change, 68, 198-208. Recuperado de http://doi. org/10.1016/j.gloplacha.2009.04.004

Zhou, K.-P., Bi, W.-H., Zhang, Q.-H., Fu, X.-H. \& Wu, G.-Q. (2016). Influence of temperature and turbidity on water COD detection by UV absorption spectroscopy. Optoelectronics Letters, 12, 461-464. Recuperado de http://doi.org/10.1007/s11801-016-6178-z 
